\title{
Analysing China's Population: Social Change in a New Demographic Era
}

\author{
edited by Isabelle Attané and Baochang Gu \\ Dordrecht: Springer Science \& Business Media 2014 \\ ISBN 978-94-017-8986-8 \\ Hardcover \$129, 270 pp.
}

\section{Reviewed by Yan Wei \\ University of Finance and Economics, School of Public Administration (PRC)}

Along with its rapid socioeconomic development over the past few decades, China experienced profound demographic transitions, and has entered into a new stage of demographic development. In the past half-century, China has completed the demographic transition and has become a country with low population growth. China's 2010 census confirms the new demographic era, characterized by prolonged low fertility, persistently elevated sex ratios, rapid aging, massive urbanization, and widespread geographic redistribution (Cai 2013). The results of 2010 census confirm a series of demographic changes that had been largely foreseen by demographers and reveal few unexpected trends. Isabelle Attané and Baochang Gu's collection of essays titled Analysis China's Population: Social Change in New Demographic Era aims to address various defining patterns of China's demographic landscape in the early twenty-first century, some of which pose severe challenges to China's government.

The 297-page collection includes 13 papers in three parts. In the first chapter, titled "China's demographic in a changing society: Old problem and new challenge," Isabelle Attané and Baochang Gu give a comprehensive review of demographic vicissitudes and social change in last few decades, and also a brief introduction of the 12 papers collected in the book. The six papers of the first part, entitled "China's low fertility: Facts and correlates," focus on concerns relating to recent fertility trends. In chapter 2, titled "China's low fertility: Evidence from the 2010 census", Zhigang Guo and Baochang Gu argue that the 2010 census reflects the true level of fertility which is far from adhering to the official TFR of 1.8. In Chapter 3, titled "Changing pattern of marriage and divorce in today's China," Jiehua Lu and Xiaofei Wang state that first marriage is increasingly delayed for both men and women, the age-specific proportions of unmarried people are growing, and divorce is now better accepted socially. In Chapter 4, titled "Education in China: Uneven progress," Qiang Ren and Ping Zhu indicate that China has achieved significant improvement in education, while progress is uneven and gaps remain, in particular between gender, ethnic groups, provinces, and place of residence. In Chapter 5, titled "The male surplus in China's marriage market: Reviews and prospects," Shuzhuo Li, Quanbao Jiang, and Marcus W. Feldman estimate the male surplus in the population and investigate the possible social and individual consequences of the male-biased sex structure. In Chapter 6 titled "Being a woman in China today: A demography of gender," Isabelle Attané draws up a socio-demographic inventory of the situation of Chinese women in demographic and socioeconomic transition.

The three papers of the second part, entitled "Modernization, social change, and social segregation," focuses on various dimensions of social inequality that have emerged or grow more acute with the transformation of economic system. In chapter 7, titled "Are China's minority nationalities still on margin?", Dudley Poston and Qian Xiong conclude that Chinese minorities are socially different from the Han majority due to centuries of spatial segregation. In chapter 8, titled "Demographic and social impact of internal migration in China," Delia Davin focuses on rural-to-urban migration flows and their impact on age and sex structure, people left behind 
in village, gender relationship. In chapter 9, titled “China's urbanization: A new 'leap forward," Guixin Wang argues that sustainable urbanization calls for more balanced development between urban and rural economics, and the necessary integration of rural migration into urban life.

The three papers of the third part, entitled "Changing age structure, labour force and the older population," address what will probably be the greatest challenge in the coming decades: the shrinkage of the working-age population that will accompany population aging. In chapter 10, titled "Urban-rural housing inequality in transitional China," Yanjie Bian and Chuntian Lu review the recent reforms in housing allocation system and argue that housing is an important constituent of inequality in both rural and urban China. In chapter 11, titled "Mortality in China: Data source trends and patterns," Zhongwei Zhao, Wei Chen, Jiaying Zhao, and Xianling Zhang address the important issue of mortality in the context of epidemiological transition. In chapter 12, titled "Dwindling labour supply in China: Scenarios for 2010-2060," Michele Bruni projects future trends between 2015 and 2030, and finds that China will be affect by a much sharper decline in its working-age population. In chapter 13, titled "The economic support system and changing age structure in China," Sanh-Hyop Lee and Qiulin Chen provide insight into some important features of recent changes in intergenerational resource allocation in China.

This collection of papers features comprehensiveness and authoritativeness. The editors clearly attempt to include the research on China's population in all aspects and the effect of population on social economy in a new situation. The essays collected are all recent research by scholars at home and broad who have made great achievement in the research of China's issues. The data utilized, primarily based on China's sixth population census data in 2010, is supplemented by all previous census data to analyze all aspects in detail, containing fertility, marriage patterns, internal migration, mortality patterns, urbanization, gender structure, and age structure. Meanwhile, minority and female populations are also analyzed, and some issues such as social inequality are discussed. The collection remains comprehensive and close to practice in analyzing and judging problems of population society, and it is informative and reliable in the data materials, thus fulfilling the intentions of the editors. The collection of papers serves as a high reference value regarding overall trends and characteristics of China's population as well as consequence of social economy, and also as an important book with regard to the study of China's population development and social transformation.

However, as a whole, this collection contains various papers but with numerous instances of jumbled and unclear categorization. Though editors try to connect socio-economic development with all chapters in the opening chapter, the 12 collected papers divided into 3 parts mostly deal with formal demography, also researches on sub-population, social inequality, and economics. There seems to be no definite standard for selecting papers and no careful classification of these papers.

In addition, several population issues touching on the Chinese circumstances are not involved in this book. From the point of view of demography, there is almost no deep research on two aspects. The first one is Chinese aging population, which is an existing problem but also a new one. Aging is slightly mentioned in many chapters of the book, but there is no special section for the Chinese aging problem, which includes, for instance, the recent situation and prediction of aging population, the features and distribution of the elderly, or the social, economic, and health conditions of the elderly. The second one is changes in Chinese family composition. The results of China's 2010 census show that the average size of family households was 3.10 persons, compared with 3.44 and 3.96 persons in the 2000 and 1990 population censuses, respectively. Family is one of the significant factors of population processes, whose size, structure, and type determine the dynamic trends and characteristics of population. In addition, other demographic issues with Chinese characteristics, such as the one-child family, parents who lost their only child, and transformation of fertility attitudes are worth further study.

After three decades of strict birth control, the rapid growth of China's population has been curbed. On 29 October 2015, the Chinese government declared full implementation of a universal two-child policy, which has drawn a heated discussion among media and individuals (Jiang and Cullinane 2015; Xinhua 2015). It is the second adjustment of fertility policy, after a selective two-child policy announced in November 2013, which means the end of 35 years of strict family planning policies. The universal two-child policy can mitigate the problems mentioned in this collection of essays, such as sex ratio, aging of population, and labour shortage. 
However, it may take some time before the policies gradually take effect, due to the longevity of the population process. The two-child policy may help China to solve some population-related challenges, but cannot reverse the general demographic trends. More integrated social policies should be designed and implemented at the same time, as a more effective means for China to tackle future development challenges, including population

problems (Peng 2013). The challenges and opportunities for China's population with the new fertility policy certainly warrant a look.

\section{References}

Cai, Y. 2013. China's new demographic reality: Learning from the 2010 census. Population and Development Review 39(3):371-96.

Peng, X. 2013. China's demographic challenge requires an integrated coping strategy. Journal of Policy Analysis and Management 32(2):399-406.

Jiang, S., and S. Cullinane. 2015. China's one-child policy to end. CNN, 29 October 2015. http://edition.cnn. com/2015/10/29/asia/china-one-child-policy/

Xinhua. 2015. China to allow two children for all couples. Xinbua, 29 October 2015. http://www.chinadaily.com. cn/china/2015-10/29/content_22312495.htm 